Department of Paediatrics,

Ludwig-Maximilians-

University of Munich,

Germany

B Koletzko

University of Central

Lancashire, UK

P J Aggett

Department of

Paediatrics, San Paolo

Hospital, Milan, Italy

C Agostoni

Department of

Paediatrics,

Ostschweizerisches

Kinderspital, St Gallen,

Switzerland

K Baerlocher

Hôpital Necker-Enfants Malades, Paris, France

J-L Bresson

Royal Victoria

Infirmary, University of Newcastle upon Tyne,

UK

R J Cooke

Department of

Paediatrics, University

Medical School of Pecs,

Hungary

T Decsi

Department of

Paediatrics, University

of Graz, Austria

J Deutsch

First Department of

Paediatrics,

Charles-University,

Prague, Czech Republic

J Janda

Research Institute of Child Nutrition, Dortmund, Germany

F Manz

Paediatric Department, Universidad Miguel

Hernandez, San Juan

(Alicante), Spain

M Moya

Department of

Paediatrics, University

of Liège, Belgium

J Rigo

The Children's

Memorial Health

Institute, Warsaw,

Poland

J Soch

Correspondence to:

Dr B Koletzko, Professor of

Paediatrics, Kinderklinik and

Kinderpoliklinik, Klinikum

Innenstadt, Ludwig-

Maximilians-University of

Munich, Lindwurmstrasse 4,

D-80337 München,

Germany.

email: berthold.koletzko@

kk-i.med.uni-muenchen.de

\title{
Pesticides in dietary foods for infants and young children.
}

\section{Report of the Working Group on Pesticides in Baby Foods of the European Society for Paediatric Gastroenterology, Hepatology and Nutrition (ESPGHAN)}

\author{
B Koletzko, P J Aggett, C Agostoni, K Baerlocher, J-L Bresson, R J Cooke, T Decsi, \\ J Deutsch, J Janda, F Manz, M Moya, J Rigo, J Socha
}

A large variety of insecticides, herbicides, and fungicides are widely used in agriculture to increase yield, control microorganisms that may produce toxic or carcinogenic metabolites, and reduce the price of food production. Such pesticides are intended to kill living organisms, and a potential dose-related acute and chronic toxicity exists in humans with an estimated 800000 cases of acute intoxications each year worldwide, including some 3000 deaths. ${ }^{12}$ The use of pesticides and their acceptable maximum concentration in foods therefore need to be regulated. Of particular concern is the exposure of infants and children to food contaminants because of their possible increased susceptibility for adverse effects. ${ }^{3-5}$ In this article we wish to comment from a paediatric perspective on the choices, which have recently been debated, for defining reliably safe maximum residue limits for pesticides in dietary foods for infants and young children in the European Union.

The directives of the European Union on infant formulas, follow on formulas, processed cereal-based foods, and baby foods state that these products "shall not contain any substance in such quantity as to endanger the health of infants and young children", and that maximum levels "shall be established without delay". ${ }^{6}$ The important premise for paediatricians is that infants should not be exposed to any unnecessary risk. The commission intends to propose maximum concentrations of pesticides in these foods by 1 January $1999 .{ }^{6}$ Such maximum concentrations are also required for organically grown baby foods which may contain residue concentrations exceeding those acceptable for infants. This is because the European Union regulations on ecological agriculture do not exclude contamination from soil, air, water, or other sources and do not provide maximum residue concentrations for organically grown foods.

At least two options exist for setting maximum residue concentrations. They may be defined for each individual contaminant, based on estimations of acceptable daily intakes (ADI) for the most susceptible parts of the population combined with estimates on the range of intakes of specific foods in these populations. A second option is to set a low general limit for any pesticide residue, aiming at the avoidance of pesticide exposure of infants and young children and any associated potential risks, as far as is practically feasible.

Defining safe maximum residue concentrations for each individual contaminant barely seems possible because there are about 800 pesticides that are permitted for use in the European Union, ${ }^{6}$ particularly as an ADI value has not yet been established for many of these compounds. ${ }^{4}$ Moreover, ADI values that do exist have been delineated from studies in vitro, in experimental animals, and from observations of toxic effects in humans, but only very limited data are available on toxic effects in human infants. Also, not much information exists on pharmacokinetics and pharmacodynamics of pesticides in developing organisms. ${ }^{1}$ Toxicity of pesticides in infants and young children may differ quantitatively and qualitatively from that in adults. Quantitative differences exist in absorption, metabolism, detoxification, and excretion, which may make infants more or less sensitive to various xenobiotics than adults. ${ }^{5}$ These differences need to be related to the specific food intakes of infants and young children that are much higher per kg body weight than in adults. For example, the estimated 95th centiles of consumption of manufactured baby foods in infants aged 12 months are as high as almost $50 \mathrm{~g} / \mathrm{kg}$ body weight per day. ${ }^{7}$

Qualitative differences in toxicity result from the particular sensitivity of a growing and developing infant where exposure can have other effects than in the steady state situation of an adult. ${ }^{8}$ For example, delayed neurotoxicity of pesticides has been observed in animal studies as a result of exposure during a susceptible period of early organ development, with a dose considered subtoxic to adults. ${ }^{1}$ Such functional toxicity of pesticides on the developing organism is not only restricted to the nervous system but has also been observed as toxicity on the developing reproductive, immune, and endocrine system. ${ }^{1}$ Little work has been done to identify long term effects after a period of 
latency, and a serious methodological limitation is that long term effects in humans cannot be reliably simulated in experimental animals. Some pesticides share a common mechanism for their toxic effects, but a lack of information exists on the effects of exposure to a combination of different pesticides in infants. The potential consequences of genetic variability within infant populations on the metabolism and biological effects of xenobiotics also are not yet known. In view of the acknowledged lack of information on toxicological effects during early human development, it was previously concluded that threshold values for ADI could not be considered applicable in infants during the first three months of life. ${ }^{59}$

The limited dataset available appears inadequate for a thorough scientific risk assessment of the short term and, particularly, long term toxicity of the many pesticides in use in infants and young children. A workshop of the International Pediatric Association recently concluded therefore that it would be prudent to apply a strict general limitation of the presence of unnecessary and potentially toxic substances in baby foods. ${ }^{10}$ The Scientific Committee for Food of the European Union has recently supported the setting of a general maximum residue concentration of $0.01 \mathrm{mg} / \mathrm{kg}$ for pesticides in foods intended for infants and young children, with the exception of those pesticides for which an individual risk assessment would indicate a lower maximum residue concentration. ${ }^{7}$ This threshold concentration of $0.01 \mathrm{mg} / \mathrm{kg}$ has been based near the limit for analytical determination of pesticides with traditional methods. Occasionally, concentrations of pesticide residues higher than these are found in breast milk, but the working group feels that the benefits which can be derived from breast feeding outweigh any possible disadvantages. The practical feasibility of a general maximum residue concentration of $0.01 \mathrm{mg} / \mathrm{kg}$ for pesticides in dietary foods intended for infants and young children, at reasonable cost, is underlined by the fact that this low threshold is already in use in several member states of the European Union, and at present some $40 \%$ of foods for babies and young children in the European Union are produced under the conditions of this limit. ${ }^{611}$ From a paediatric perspective, we support the application of this strict maximum residue concentration until a better basis for a more reliable estimation of maximum residue concentrations for individual toxicants may become available, as well as a more extensive evaluation of the hazards posed to infants by pesticide residues.

We are grateful to the charitable Child Health Foundation, Munich, Germany for generous financial support of a workshop on pesticides in baby foods held at the 1998 Annual Meeting of the European Society for Paediatric Gastroenterology, Hepatology and Nutrition (ESPGHAN), out of which this comment ogy and
evolved.

1 Schilter B, Huggett AC. The ADI as a basis to establish standards for pesticide residues in food products for infants and young children. Food Additives and Contaminants 1998;15(suppl):83-9.

2 Manz F. Residues of pesticides in baby food. International fournal of Child Health 1996;7:3-11.

3 Larsen JC, Pascal G. Workshop on the applicability of the ADI to infants and children: consensus summary. Food Additives and Contaminants 1998;15:suppl:1-9.

4 National Research Council. Pesticides in the diets of infants and children. Washington DC: National Academy Press, 1993.

5 Ostergard G, Knudsen I. The applicability of the ADI (acceptable daily intake) for food additives to infants and children. Food Additives and Contaminants 1998;15(suppl): 63-74.

6 European Commission. Directorate general III. Working document for discussions of options to amend commission directives 91/321/EEC and 96/5/EC in order to introduce maximum residue limits of pesticides for foods intended for infants and young children. Brussels: European Commission, February 1998: III/ $/ 5110 / 98$

7 European Commission. Further advice on the opinion of the Scientific Committee for Food expressed on the 19 September 1997 on a maximum residue limit (MRL) of $0.01 \mathrm{mg} / \mathrm{kg}$ for pesticides in foods intended for infants and young children. Brussels: European Commission, Directorate General XXIV, Consumer Policy and Health Protection, 1998.

8 Dencker L, Ericjsson P. Susceptibility in utero and upon neonatal exposure. Food Additives and Contaminants 1998; 15(suppl):37-43.

9 World Health Organisation. Principles for the safety assessment of food additives and contaminants in foods. Environmental of food additives and contaminants in foods

10 IPA/UNICEF Workshop. Environmental health hazards in pregnancy and early childhood. International fournal of Child Health 1996;7:27-9.

11 von Mühlendahl KE, Otto M, Manz F. Pesticides in baby food: a European issue. Eur F Pediatr 1996;155:417-18. 